\title{
13. Policy Mismatch and Indigenous Art Centres: The tension between economic independence and community development
}

\author{
Gretchen Marie Stolte
}

The concept of 'one size fits all' is an alluring one. It implies that no matter what an object's physical shape, there is a universal 'fit' that will suit. There is no big or small, no high or low; the one-size-fits-all model eliminates the need for the accommodation of difference. It is thus no surprise that the onesize-fits-all model would be the ultimate aphrodisiac for policymakers working in Indigenous affairs. This of course leads to real problems because, as many know, the one-size-fits-all model might work well within the average but poorly within the extremes. This chapter looks at a small section of a recent Australian Government report that focuses on a single model for Aboriginal and Torres Strait Islander art centres, and critiques that model as something counterproductive and ultimately destructive for the health of the communities involved in arts production.

\section{The Report}

In August 2006, the Senate Standing Committee on Environment, Communications, Information Technology and the Arts (hereinafter the Report) began an inquiry into and report on the Indigenous visual arts and craft sector. The purpose of this inquiry was to establish

1. the current size and scale of Australia's Indigenous visual arts and crafts sector;

2. the economic, social and cultural benefits of the sector;

3. the overall financial, cultural and artistic sustainability of the sector;

4. the current and likely future priority infrastructure needs of the sector;

5. opportunities for strategies and mechanisms that the sector could adopt to improve its practices, capacity and sustainability, including to deal with unscrupulous or unethical conduct; 
6. opportunities for existing government support programs for Indigenous visual art and crafts to be more effectively targeted to improve the sector's capacity and future sustainability; and

7. future opportunities for further growth of Australia's Indigenous visual arts and craft sector, including through further developing international markets. (SSCECITA 2007a:1)

As illustrated in the number of references, the concept of sustainability was an important one for the committee. As will become evident, however, implied within ideas of sustainability are issues of economic independence from government funding. This implication is made apparent in the Report's association of success with the amount of funding an art centre receives from the Government: an art centre is successful if it is financially independent from Commonwealth funding and, therefore, unsuccessful if it is receiving such funding. The committee then mentioned two (of the 110) art centres that achieved such 'success'.

On Wednesday, 21 February 2007, the Senate Report held a hearing in Alice Springs, NT, to hear from stakeholders within the Indigenous arts and craft sector. When talking with the Manager of Papunya Tula, Paul Sweeney, Chairman Eggleston stated:

I love the fact that you are not getting any government money...At the same time, you are doing that community development work, and I acknowledge very clearly that the art centres do that community development work. It is not just an art area; it is a community development area as well. But you seem to be doing the same and you are doing it all without a cent of government money. Why isn't your model the right model for everyone? (SSCECITA 2007b:10)

Sweeney's response was understandably vague, stating that his experience was limited to Papunya Tula only and that he could not speak for other art centres (SSCECITA 2007b:10). Eggleston's assumption that 'you seem to be doing the same' reflects his lack of knowledge of local art histories that created the Central Desert art movement and Papunya Tula's success, but also exemplifies how the Chairman equated Papunya Tula's on-the-ground involvement with other art centres. Is the Papunya Tula model the right model for everyone? Can there be a single, one-size-fits-all model for Indigenous art centres so the flow of government money is no longer needed or required? Should that even be the goal? It is necessary to outline some of the definitions, functions and roles of art centres in order to highlight the diversity as well as the challenges facing these institutions. Before doing so, I would first like to set the framework through which it is most beneficial to view an art centre. 


\section{Defining an Aboriginal Art Centre Cross-Culturally}

Howard Morphy writes that anthropology by definition is a 'form of crosscultural discourse [that] establishes equivalences through the creation of cross-cultural categories' (Morphy 2008b:8, 9). Some examples of crosscultural categories include religion, kinship, marriage, land rights and artistic practices. The challenge of a cross-cultural definition is to 'allow what was and is different...to remain despite its placement within a more inclusive category' (Morphy 2008b:3). Morphy warns against taking the concept too far, writing that some categories are more limited than others and universalisms must 'always be open to question' (Morphy 2008b:7). I argue that art centres need to be treated as a cross-cultural category - to recognise what was and is differentand that the Senate Report does little to develop such distinctions. This lack of critical awareness is evident throughout the Report, as what is different about an Indigenous art centre is subsumed into broad definitions regarding general business practices.

Seeing art centres as cross-cultural categories is to go beyond an art centre as an arm of the arts industry. A cross-cultural art centre category allows for art centres to also go beyond being simple service providers. Although certainly not true for all art centres operating in Australia, some art centres have become the cultural hub of a community where the continuation of language, traditions and ceremonies is renewed, reinvented and put on display.

The cross-cultural category of 'art centre' is not a universal one and must be understood in both a Western framework and an Indigenous one. Associating the success of an art centre with its level of government funding is tantamount to defining success in such a narrow framework as to ignore the numerous activities in which an art centre engages. So what is an Indigenous art centre?

Indigenous art centres are defined in many different ways. The Senate Report defines an art centre as 'an Indigenous owned and operated entity, generally located on an Indigenous community' (SSCECITA 2007a:27). The Australia Council for the Arts (2007) defines a community art centre as a creator of 'bridges of understanding, regeneration and opportunity', but definitions of an Indigenous art centre can also vary according to their functions and obligations. In The Art \& Craft Centre Story, Felicity Wright defines an art centre as 'any organization operating in remote Australia that is owned and controlled by Aboriginal people, where the principal activity is facilitating the production and marketing of arts and crafts' (1999:7). Wright's definition focuses on the commercial aspect of an art centre, but the rest of her report does much to describe the socio-cultural aspects as well. The Association of Northern, Kimberley and Arnhem Aboriginal Artists (ANKAAA) defines an art centre's roles as a protector 
of cultural property, as a resource for materials and as a general arts and culture facilitator. Finally, most definitions of art centres emphasise that art centres are located on country where opportunities for Indigenous people are limited.

DesArt, the Association of Central Australian Aboriginal Art \& Art Centres, outlines the seven roles of an art centre: as a place for cultural maintenance, as a place of emotional and personal renewal, as a place of work and earning income, as a distributor to markets, as an avenue for strengthening the community, as a place of learning and as a place of respite and care (SSCECITA 2007a:30). DesArt is also quick to point out the many other services provided beyond art production and marketing. The social benefits include: a safe place to meet and talk, a place for help in filling out government forms, accessing the Internet, finding a ride to another community, and allowing space in which youths can engage in cultural activities (SSCECITA 2007a:30). Another key benefit and service provided is cultural maintenance for which art centres are a 'significant contributor in sustaining a cohesive and socially healthy community' (SSCECITA 2007a:32). A recent conversation I had with one of the leaders of the art centre in New Mapoon, located on the Cape York Peninsula in Queensland, stressed not only the economic benefits of being able to sell their artwork but also the benefit of publicly displaying the artefacts and works that have taken on communitywide cultural significance (New Mapoon Art Centre, Personal communication, 29 June 2010). In places such as New Mapoon, artworks become a source of community pride and are displayed and cared for in order to maintain a strong cultural identity.

As might be becoming clear, art centres do more than just art production - or they at least can do more, if given the space to do so. Given the diversity of Aboriginal communities across remote Australia, one cannot define an art centre based on a single definition. The Department of Communications, Information Technology and the Arts (DCITA) recognises this reality. DCITA states that 'some art centres operate as highly successful enterprises while others have more of a community arts development focus' (SSCECITA 2007a:33); in other words, some art centres are more industry based while others are more service based. The juxtaposition of a 'highly successful enterprise' with and even against the 'community arts development focus' is an important one. Within DCITA's statement exists the crux of the problem in desiring a single art centre model. Which one of the art centres is the one to be modelled after? This is especially problematic in the arts industry where fads and trends can dictate success as much as hard work and sound business practice. If art centres can be defined in so many different ways, how feasible is it to develop a single business model?

With a strong idea of the variety of different functions and objectives art centres occupy in general, it is beneficial to compare two art centre models in order to appreciate how complicated the desire for a single model can be. I have 
chosen Papunya Tula Artists (PTA) and Maningrida Arts \& Culture (MAC) as the two models to compare based on their differences in structure and their similarities in success. This comparison illustrates how their different levels of and approaches to their engagement with their prospective communities will form the basis of a discussion on how focusing on 'economic independence' is problematic at best. More importantly, this comparison only uses information taken directly from the Report and its submissions as an example of how the Senate sees differences between art centres versus how that information was put to them. Afterwards, I will put forward some considerations the Report did not include and, in this way, hope to draw out how the Report conceptualises an art centre in its search for a one-size-fits-all model.

\section{Two Models: PTA and MAC}

Papunya Tula Artists (PTA) is an arts organisation owned and operated by Aboriginal artists comprising Luritja and Pintupi language groups (PTA 2007:1). PTA supports 160 artists in three communities - Papunya, Kintore and Kiwirrkura - and, at the time of the Report,functioned with nine full-time and two part-time staff and a fleet of four Toyota Troop-Carriers. The company is selffunded and has been without government support for more than 10 years. The aim of the PTA is 'to promote individual artists, provide economic development for the communities to which they belong, and assist in the maintenance of a rich cultural heritage' (PTA 2007:1). PTA's community involvement work includes helping to raise more than $\$ 900000$ for a swimming pool in the Kintore community and, from 2000 to 2007, donating more than \$1 million towards a remote renal dialysis unit and associated programs (PTA 2007:2).

PTA's approach to its artists is fundamental to its success. The Troop-Carriers are used to deliver canvas and art materials to the communities where the artists execute their work on country (SSCECITA 2007c:8-9). PTA states that it is committed to its artists and admits to 'being very fortunate in that there is a great deal of natural talent in the area where we work' where 'basically, it comes back to a very good product which compares well on the market' (SSCECITA 2007c:8).

In comparison, Maningrida Arts \& Culture (MAC) is located in central Arnhem Land and is one of the oldest Aboriginal art centres in Australia, supporting 790 artists in more than 34 outstations (SSCECITA 2007b:42; MAC 2007:1). MAC has a 'total acquisition policy', which means that the art centre buys all works presented to its doors. As stated in their submission to the Senate Report, this practice 'creates certainty and security for artists, ensures that their work is 
treated with respect, encourages the career of young and emerging artists and provides an income to ageing artists who are no longer producing their best work' (MAC 2007:1).

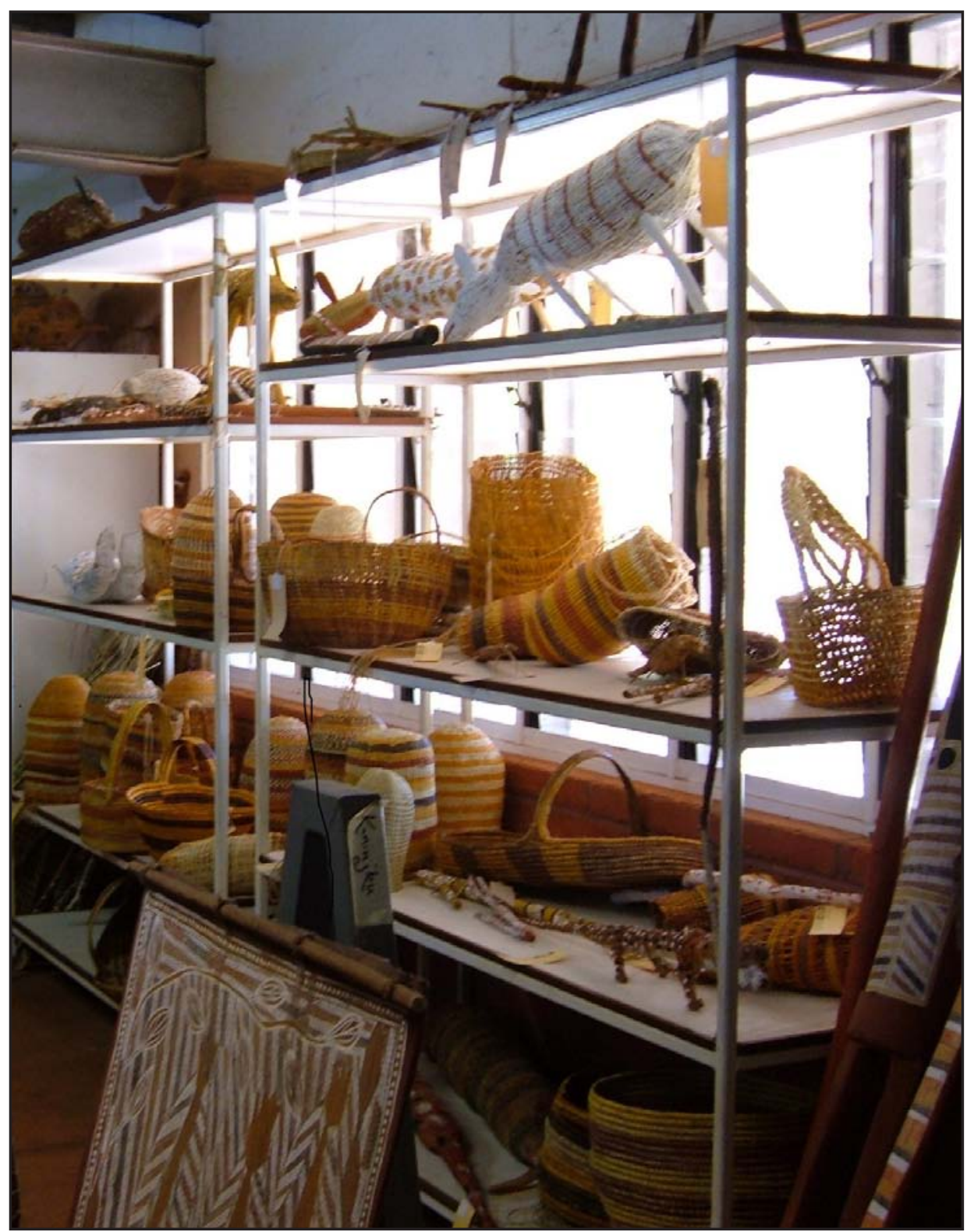

Figure 13.1 Maningrida Art Centre, 2005

Photo: By the author. 
MAC has 10 full-time staff, with the National Arts and Crafts Industry Support (NACIS) program funding the salaried positions, and with six Aboriginal staff under the Community Development Employment Projects (CDEP) scheme (MAC 2007:2). During the financial year 2005-06, MAC's turnover was \$1.7 million, with $\$ 1.1$ million given directly back to the artists (SSCECITA 2007b:42). In addition to buying and selling art, MAC engages in many cultural maintenance activities such as: the production of dictionaries and musical recordings, preserving community archives, supporting researchers and students, and more than 20 exhibitions across Australia and the world (MAC 2007:2). MAC is also one of the largest employers of Aboriginal people within its region (MAC 2007:1).

\section{Two Models: The comparison}

If economic independence from government funding is the most desired trait in an art centre, why is PTA not the model for all art centres? In summing up the committee's view on the success of art centres, it is clear PTA was held up as one of the models for success. The Report states that, along with the Jirrawun Arts Corporation, 'these organisations currently require no government support, while delivering significant benefits to their communities' (SSCECITA 2007a:47). The committee recommended that an understanding of these organisations will help 'identify potential pathways for success of Indigenous arts business' (SSCECITA 2007a:47). Moreover:

The committee is aware that there is a range of views about how art centres should do business, but it appears clear that one of the secrets to Papunya Tula's commercial success has been its aggressive and disciplined approach to the market, a well as its careful nurturing of long-term relationships with artists. (SSCECITA 2007a:48, emphasis added)

What should become apparent, however, are the major differences between MAC's engagement with its community and PTA's engagement. How does an 'aggressive and disciplined approach' translate into community development and involvement? Where does New Mapoon's desire for a cultural space come into play? If one were to compare dollars donated or large-scale projects funded, PTA would be the ideal model; the Report demonstrates quite clearly the amount of money PTA donates back into the communities. Furthermore, MAC's 'total acquisition policy' is not without its drawbacks. Sometimes, MAC acquires material that is hard to turn around and sell. For example, there can be an over-abundance of fibre work and beaded jewellery. So what are the benefits of a MAC model? 
First, PTA's funding and financial successes are based on circumstances that border on the serendipitous. Papunya Tula, as Sweeney as stated, does have extraordinary talent - or at least extraordinarily marketable talent. The 2007 show at the National Museum of Australia (NMA) Papunya Tula: Out of the desert showcased this (NMA 2007b). NMA states that 'Central and Western Desert artists at Papunya, in Australia's Northern Territory, created a body of work that transformed understandings of Aboriginal art' (NMA 2007b). This type of internationally acclaimed cultural transformation does not happen more than once if it happens at all. As Peter Thorley and Andy Greensdale have demonstrated in their chapter (Chapter 11, this volume) on the importance of the interpersonal in creating a viable art market, there are many mitigating circumstances to an art centre's success.

Building models on circumstances such as those at Papunya is really to look at a unique situation - one that cannot be expected to be replicated. Thinking otherwise is to ignore the unique historical underpinnings of Aboriginal art's success. It is to ignore local art histories and the great variation of Indigenous art theories and practices. As Howard Morphy writes regarding the success of Yirrkala bark paintings, there was a tenuous thread that connected the events and collectors that produced a viable art market in Yirrkala (Morphy 2008b:58). Acknowledging art centres as a cross-cultural category includes recognising those local art histories and complexities, which give rise to the many different Aboriginal art centre models that exist in Australia and also the different levels of success.

Finally, the community work of PTA is not the same as the community work of other art centres such as MAC. Papunya Tula Artists Proprietary Limited is a corporation, not a community art centre. PTA might be involved in community development, but, swimming pools and medical equipment aside, it is not the same type of community involvement in which MAC engages. It is not just a matter of scale, priorities or resources. It is all of those things. The cultural archiving, the support of researchers and students, the production of dictionaries and the recordings of music are a few examples of the level of the cultural maintenance and community involvement of MAC. Above all, PTA supports and sponsors 160 artists whereas MAC supports almost 800 artists. Maningrida's total acquisition policy involves more Aboriginal people in the arts development program and stretches the centre's resources across a broader region. If MAC were forced to be more 'economically responsible', one of the first changes would have to be to their acquisition policy. This means less people involved in the arts, less communication of cultural knowledge and less stability for Aboriginal communities. In addition, being more critical of acquisition does not guarantee greater financial success, only the decrease of involvement of Aboriginal artists in the market. 
Importantly, let me make it clear that I am not proposing one model over another. PTA and MAC have different arenas of success and different priorities. One is not better than another. It is because of this difference - the difference of all Indigenous art centres across Australia - that it is problematic to choose one art centre model over another. If a choice has to be made, it should be for the model that works for that community.

As Wright acknowledges in her report's summary, 'Aboriginal community art and craft centres are not conventional businesses. They operate in communities where educational, enterprise, and employment opportunities are extremely limited, and they fulfil important sociocultural and training functions in addition to their commercial activities' (Wright and Morphy 1999:5). These socio-cultural functions would be jeopardised if art centres such as MAC were modelled on art centres such as PTA - being more 'aggressive and disciplined' over other priorities MAC and its communities have chosen or might choose to pursue. Wright notes the objectives of art centres are not fixed and are an amalgam of cultural and commercial enterprises (Wright and Morphy 1999:6). This is one of the reasons that recognising an art centre as a cross-cultural entity and not strictly a Western institution simply located on Aboriginal land is so important.

Further, the Report does not address many of the messy issues that exist within the arts industry. For example, what are the contractual agreements between artists and art centres? Are there exclusivity clauses that bar artists from exhibiting elsewhere and thus potentially reduce outside sources of income? Can anyone located on country have access to art centre materials and resources? Do you have to live on country? How are the businesses structured, and how are the administration systems set up? Who is on the board, who can be on the board and how much power do those people have to change existing structures and systems? How much creativity are the artists allowed or are the canvas sizes and paint colours dictated by unseen managers? The Australian Indigenous art sector is a highly politicised and volatile arena and yet none of those aspects made it into the Report with regards to how art centres are run or structured. The search for a one-size-fits-all model was a sanitised and misdirected endeavour at best.

\section{Conclusion}

The Report acknowledges that 'art centres have two key cultural roles: they facilitate the maintenance of Indigenous culture within the community, as well as facilitating the transmission of that culture to the world beyond the community' (SSCECITA 2007a:30, original emphasis). In addition, the 'maintenance 
of cultural practice is also recognised by the [art centre's] community as a significant contributor in sustaining a cohesive and socially healthy community' (SSCECITA 2007a:32). Despite recognising the importance of the relationship an art centre has with its host community beyond art production, the three major recommendations the Report makes with regards to funding do not. Turning to these recommendations, they are as follows.

\section{Recommendation 5}

4.77 The committee supports the roles of DEWR [Department of Employment and Workplace Relations] and Indigenous Business Australia [IBA] programs in assisting where appropriate the transition to economic independence for art centres, and recommends that these initiatives be further promoted by DEWR and IBA and utilised by art centres.

\section{Recommendation 6}

4.78 The committee recommends that the Commonwealth further expand funding under the existing NACIS scheme and consider revising its guidelines to confine its use to non-infrastructure projects.

\section{Recommendation 7}

4.79 The committee recommends that the Commonwealth consult with stakeholders in the industry, particularly DesArt and ANKAAA, on reforms to NACIS funding criteria, so that funding decisions are guided in part by the aim of ensuring operation of art centres in accordance with best practice principles. These standards may include (but not be confined to):

- staffing requirements that meet the operational needs of art centres, and ensure flexibility to accommodate any particular requirements of such centres;

- governance and reporting systems; and

- training commitments, including financial, management and art education components.

(SSCECITA 2007a:50-1)

First and foremost is the recommendation to provide help to move art centres towards economic independence. The underlying assumption here is that it is only a matter of time before an art centre is economically independent, and it is simply a matter of proper education and infrastructure before that happens. Second, the recommendation asks for consideration in help in funding for 'noninfrastructure' projects and/or the flexibility to 'accommodate any particular 
requirements'. Are these the terms that are to be defined as those schemes that aide in cultural continuity and social cohesion? In the end, it seems that the recommendations, as extensions of the Report's understanding of this sector, do little to encourage general community involvement or support practices for cultural continuity and exchange as those concepts are subsumed under 'bestpractice principles'. This is highly disappointing as the Report does make a good effort at illustrating the many different ways an art centre can be defined and their subsequent roles.

This chapter aimed to critically engage with the 2007 Senate Report into the Indigenous art sector and question the need for a single art centre model while arguing that art centres need to be understood within a cross-cultural category. Such recognition would not only require keeping the nuanced definitions regarding what an art centre is, what it should do and its priorities but would also expand the inquiry into the complex business structures and problems that exist. Morphy states that 'the distinctive art styles associated with different community art centres are in part the product of local art histories: people working together in a community and creating works that express their contemporary regional identity' (2008b:11). Seeing art centres as a crosscultural category - needing to be defined as neither wholly Indigenous nor wholly mainstream - is important with regards to an arts policy and subsequent funding decisions. This is in part because there are so many different art centres, reflecting their different communities. Horribly absent from this report are the voices of the Indigenous artists who participate in and enjoy the benefits of art centres. Where are the on-the-ground stories? I have had the opportunity to ask some artists about their engagements with art centres and the reasoning focuses on cultural maintenance first and economic benefits last. Where is this understanding, this voice, in the Senate Report? It is in finding this voice that Morphy's cross-cultural category is an appealing model for researching the Indigenous arts sector because it demands perspectives from both Indigenous and non-Indigenous participants.

This volume is about Indigenous participation in the Australian economy. To make a business economically independent and sustainable (and this is no small feat), Papunya Tula's 'aggressive and disciplined' approach is admittedly necessary. Given the huge amount of community involvement most art centres engage in though, any aggressive and disciplined approach would jeopardise the art centre's ability to function in a healthy socio-cultural capacity. Art centres are engaged with so much more than just art 'production' and yet are continually under government pressure to be self-funded. In investing in art centres, the Government must take into account what the art centre does and does not do in policy's expectations of economic independence. Funding must take into consideration levels of community involvement in which the Commonwealth is 
not participating or present but which are extremely important to Indigenous participants. Aboriginal and Torres Strait Islander community art centres must not be viewed through the same lens as a mainstream business located in downtown Sydney. Art centres are so much more than just businesses and that needs to be recognised. In this case, one size does not fit all.

\section{References}

Altman, J. 2003. Developing an Indigenous arts strategy for the Northern Territory: issues for papers in consultations. CAEPR Working Paper No. 22/2003, Centre for Aboriginal Economic Policy Research, Australian National University, Canberra. Viewed 10 April 2008, <http:/www.aph.gov.au/ senate/committee/ecita_ctte/completed_inquiries/2004-07/indigenous_arts/ submissions/sublla.pdf>

Altman, J. 2007. Submission to the Inquiry into Australia's Indigenous Visual Arts and Craft Sector. Submission 11. Viewed 10 April 2008, <http://www. aph.gov.au/senate/committee/ecita_ctte/completed_inquiries/2004-07/ indigenous_arts/submissions/sub11.pdf $>$

Association of Northern, Kimberley and Arnhem Aboriginal Artists (ANKAAA) 2007. Submission to the Inquiry into Australia's Indigenous Visual Arts and Craft Sector. Submission 63. Viewed 10 April 2008, <http://www.aph.gov. $\mathrm{au} /$ senate/committee/ecita_ctte/completed_inquiries/2004-07/indigenous_ arts/submissions/sub63.pdf>

Australia Council for the Arts 2007. The Arts: Community arts. Viewed 5 June 2008, <http://www.australiacouncil.gov.au/the_arts/community_arts>

Maningrida Arts \& Culture (MAC) 2007. Submission to the Inquiry into Australia's Indigenous Visual Arts and Craft Sector. Submission 51. Viewed 10 April 2008, <http://www.aph.gov.au/senate/committee/ecita_ctte/ completed_inquiries/2004-07/indigenous_arts/submissions/sub51.pdf >

Morphy, H. 2008a. Acting in a community - art and social cohesion in Indigenous Australia. Humanities Research XV (2).

Morphy, H. 2008b. Becoming Art: Exploring cross-cultural categories. Sydney: UNSW Press.

National Gallery of Australia 2007. Annual Report 2006-07. Canberra: National Gallery of Australia. Viewed 3 June 2008, <http://www.nga.gov.au/AboutUs/ Reports/AR07> 
National Museum of Australia (NMA) 2007a. Annual Report 2006-2007. Canberra: National Museum of Australia. Viewed 3 June 2008, <http:// www.nma.gov.au/shared/libraries/attachments/annual_report/annual_ report_2006_2007/annual_report_2006_2007_parts_3_to_5/files/21134/ NMA_Annual_Report_06-07_parts_3_4_5_electronic_optimised.pdf $>$

National Museum of Australia (NMA) 2007b. Papunya Tula: Out of the desert. Canberra: National Museum of Australia. Viewed 9 June 2008, <http://www. nma.gov.au/exhibitions/papunya_painting/>

North Sydney Community Centre 2006. History of North Sydney Community Centre. Viewed 4 June 2008, last updated 26 September 2006, <http://www. northsydneycentre.com.au/history-of-north-sydney-community-centre. php\#Artists>

Papunya Tula Artists Proprietary Limited (PTA) 2007. Submission to the Inquiry into Australia's Indigenous Visual Arts and Craft Sector. Submission 14. Viewed 1 June 2008, <http://www.aph.gov.au/senate/committee/ecita_ctte/ completed_inquiries/2004-07/indigenous_arts/submissions/subl4.pdf>

Senate Standing Committee on Environment, Communications, Information Technology and the Arts (SSCECITA) 2007a. Indigenous Art-Securing the future: Australia's Indigenous visual arts and craft sector. Canberra: Standing Committee on Environment, Communications, Information Technology and the Arts.

Senate Standing Committee on Environment, Communications, Information Technology and the Arts (SSCECITA) 2007b. Inquiry into Australia's Indigenous Visual Arts and Craft Sector: Public hearing transcript-Darwin, 20/02/07. Viewed 10 April 2008, <http://www.aph.gov.au/hansard/senate/ commttee/S9977.pdf>

Senate Standing Committee on Environment, Communications, Information Technology and the Arts (SSCECITA) 2007c. Inquiry into Australia's Indigenous Visual Arts and Craft Sector: Public hearing transcript-Alice Springs, 21/02/07. Viewed 10 April 2008, <http://www.aph.gov.au/hansard/ senate/commttee/S9978.pdf>

Wright, F. 1999. The Art \& Craft Centre Story. Volume one: Report. Canberra: Aboriginal and Torres Strait Islander Commission.

Wright, F. and Morphy, F. (eds) 1999. The Art \& Craft Centre Story. Volume two: Summary and recommendations. Canberra: Aboriginal and Torres Strait Islander Commission. 